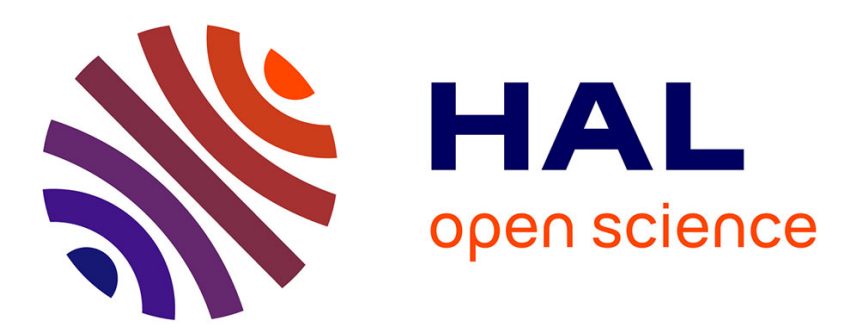

\title{
Underpinning Strategic Behaviours and Posture of Principal Investigators in Transition/Uncertain Environments
}

\author{
Conor O'Kane, James Cunningham, Vincent Mangematin
}

\section{To cite this version:}

Conor O'Kane, James Cunningham, Vincent Mangematin. Underpinning Strategic Behaviours and Posture of Principal Investigators in Transition/Uncertain Environments. 2012. hal-00794944

\author{
HAL Id: hal-00794944 \\ https://hal.science/hal-00794944
}

Preprint submitted on 26 Feb 2013

HAL is a multi-disciplinary open access archive for the deposit and dissemination of scientific research documents, whether they are published or not. The documents may come from teaching and research institutions in France or abroad, or from public or private research centers.
L'archive ouverte pluridisciplinaire HAL, est destinée au dépôt et à la diffusion de documents scientifiques de niveau recherche, publiés ou non, émanant des établissements d'enseignement et de recherche français ou étrangers, des laboratoires publics ou privés. 


\title{
Underpinning Strategic Behaviours and Posture of
}

\section{Principal Investigators in Transition/Uncertain}

\author{
Environments
}

\section{Authors:}

\section{Conor O'Kane, (corresponding author)}

Department of Management, University of Otago, Dunedin, New Zealand

Email: conor.okane@otago.ac.nz

Phone: (0064) 34798121

\section{James Cunningham,}

Centre for Innovation and Structural Change, NUI Galway, Galway Ireland Email: james.cunningham@nuigalway.ie

\section{Vincent Mangematin}

Grenoble Ecole de Management, Grenoble, France

Email: mailto:vincent.mangematin@grenoble-em.com

\section{Paul 0'Reilly,}

Faculty of Business, Dublin Institute of Technology, Dublin, Ireland

Email: paul.oreilly@dit.ie

\footnotetext{
${ }^{1}$ The authors would like to thank the Irish Research Council for the Humanities and Social Sciences who provided funding for this research
} 


\title{
Underpinning Strategic Behaviours and Posture of
}

\section{Principal Investigators in Transition/Uncertain}

\section{Environments}

\begin{abstract}
Although principal investigators (PIs) are becoming key strategic actors in shaping new scientific trajectories, little is known about how they strategise in an evolving publicly funded research environment. Drawing on thirty interviews and extensive documentation from Ireland's science, engineering and technology (SET) sector, we take a closer look at the heretofore neglected strategic behaviours underlying the research activities of PIs. Our findings suggest that their strategic behaviours fall into four categories - research designer; research adapter; research supporter and research pursuer. We find that the mechanisms for selecting research strategies are interwoven with the posture (reactive/proactive) of PIs as well as their degree of conformance. We argue that more proactive PIs utilising non-conformance strategies shape new research trajectories, while conformative and/or more reactive PIs predominantly pursue and deepen existing trajectories. We discuss the wider implications of these findings for policy makers, funding bodies and the practicing PI and strategist.
\end{abstract}

Keywords: Publicly funded research; strategy; principal investigator; strategic posture.

\section{Introduction}


The public funding research environment is in a state of transition that is transforming both the nature of research and the competitive dynamics by which external monies are secured. Principal investigators (PIs) are scientists who orchestrate new research projects, combine resources and competencies (Kidwell, 2012), deepen existing scientific trajectories or shape new areas (Casatiand Genet, 2013). Appendix 1 exhibits a comprehensive list of definitions from funding bodies and leading universities. PIs are key strategic actors within this evolving environment. Paying greater attention to publicly funded PIs is necessary for us to better understand how these strategists interact with and shape their environment. While some attention has been directed at the importance of strategy to the work and organisation of research scientists (Zuckerman and Cole, 1994, Simpson and Powell, 1999; Laudel, 2006; Morris and Rip, 2006), little is known about how PIs strategise. This lack of understanding constitutes a problem as it inhibits both PIs from improving, as well as the funding agencies from effectively evaluating their performance (Adler et al., 2009; Cunningham et al., 2013). This article investigates the strategic behaviours of PIs in shaping successfully funded research projects. In examining how they balance curiosity and opportunity boundaries; and scientific freedom and conformance, we find that proactive PIs utilising non-conformance strategies shape new research trajectories, while conformative and/or reactive PIs predominantly pursue and deepen existing trajectories. Focusing on publicly funded PIs in this manner is important given that their strategic behaviours underpin the envisioning and articulation of new research trajectories, innovations and scientific discoveries, which in turn influence policy priorities, funding agendas and industry needs.

To examine the strategic behaviours of leaders acting in a transitional environment, we develop two key constructs that inform the strategic behaviours of PIs. First, we draw on the theory of exploration and exploitation in organisational adaptation and learning to describe the strategic posture of PIs as being more "reactive" (Randall et al., 2011) or "proactive" (Prieto, 2010). The notion of strategic posture reflects how PIs shape their projects in a proactive or reactive way in a transitional environment. Second, we explore the effects of conformance and how PIs might shape research projects to conform with funding agencies' and public sector research organisations' expectations rather than prioritizing scientific ambition (scientific ambition). We develop the construct of funding application conformance from the literature detailing the influence of peer review funding on research creativity and originality. Together our 
constructs reflect how choice of research in science must balance curiosity and opportunity boundaries (Bozeman and Mangematin, 2004; Fisher, 2005; Franzoni, 2009; Porac et al., 2004). The study context is Ireland's publicly funded science, engineering and technology (SET) sector. Using semi-structured interviews and extensive PI and project documentation, the study examines the strategic behaviours of thirty PIs leading National and European collaborative research projects.

Our findings contribute to strategic knowledge by emphasising how competitive actors deal with conformance pressures and strategise in transition and uncertain environments. Specifically, our contribution is an insight into the strategic behaviours underlying the research activities of publicly funded PIs. Combining pro and re-activity with conformance, four strategic behaviours have been identified: research designers (more proactive and non-conformative); research adapters (more reactive and potentially non-conformative); research supporters (more proactive and conformative) and research pursuers (more reactive and conformative). Characterising the behaviours of PIs in this manner serves to highlight the role of strategists in organisations, and specifically how they shape/reshape boundaries both within the organisation and between the organisation and its environment. We find that more proactive and nonconformative strategists are the ones who challenge existing trajectories and who shape new trajectories, while the three other categories reinforce existing trajectories. These findings are of particular interest to policy makers and funding bodies that have a key role in providing scientists with the necessary skills, funding and policies to generate new knowledge and opportunities for business exploitation. Specifically, we encourage policy makers to be aware that insufficient resource allocation and/or strategic decisions under strong conformance mechanisms serve to discourage proactive exploration and groundbreaking research strategies, particularly among less experienced strategists.

The paper begins by portraying the PI as a strategic actor and then introduces the study's two key constructs, namely strategic posture and funding conformance. We then detail our study context as well as the method, data and the analysis undertaken. Following on from this, we introduce our four strategic behaviour categories. The paper draws to a close with a discussion on our empirical findings and some concluding comments. 
STRATEGIC POSTURE OF PIS IN BETWEEN ORGANISATIONAL CONFORMANCE AND

SCIENTIFIC FREEDOM

How strategists choose to respond to competitive situations depends on their understanding and interpretation of the competitive environment (Jarratt and Stiles, 2010). The adoption of a particular strategic posture, as Smart and Vertinsky (1984) suggest, depends upon the interplay of their perceived ability to control the environment and the economics of change. Proactive behaviours to shape boundaries and challenge existing markets and frontiers require an organisational context that supports emergent strategies. Likewise, proactive strategists in the academic field will require less centralisation and greater levels of autonomy to shape future trajectories. At the opposite, reactive strategies (Randallet al., 2011) are formed to adapt environment evolutions and to promote on-going adaptations.

Within uncertain and transitional publicly funded research environments, the research activities and strategic postures of PIs straddle a need for conformance and a longingness for scientific freedom. In this increasingly dynamic and competitive environment, they must learn to manage paradoxical strategies strategies associated with contradictory, yet interwoven tensions (Smith et al., 2010). The challenge for PIs, like other strategists, is captured by James Brian Quinn (1995) when commenting "the essence of strategy ... is to build a posture that is so strong (and potentially flexible) in selective ways that the organization can achieve its goals despite the unforeseeable ways external forces may actually interact when the time comes." PIs then must select a strategic posture that is sufficiently competitive to secure public funding, and has the potential to push scientific boundaries and to open up new trajectories and collaborations academic and industrial (Mangematin et al., 2013). It also means that PIs need to develop strategic flexibility to effectively respond to opportunities in the general environment as well as charting a course through the task environment of their organisation. This requires that PIs continually achieve co-alignment of organisational resources with environmental conditions (Bourgeois, 1980). These challenges suggest it is both appropriate and timely to explore the dimensions of PIs' strategic behaviour i.e., the degree of proactivity/reactivity and the level of conformance. 


\section{Strategic postures of principal investigators}

The theory of exploration and exploitation in organisational adaptation and learning (Levinthal and March, 1993; March, 1991) provides a useful platform to conceptualise the strategic postures of PIs when conducting their research. Within a competitively funded environment, exploration and exploitation research activities compete for limited resources. Just as March's work emphasises the need to balance exploration and exploitation, PIs and funding bodies must decide to what extent they will concentrate on both activities. Recognising which type of activity PIs focus on when shaping their research projects can help us understand whether they adopt a more proactive or reactive strategic posture. The following section details how exploitation/exploration and the design school of strategy can inform both postures.

\section{Research exploitation and the "reactive" principal investigator}

Exploitation in research looks to utilise, modify and progress existing technologies, frameworks and knowledge accumulated during past experience. Research activities in this space predominantly focus on refinement and are associated with short-termism, production, execution and incremental developments (March, 1991). In line with broader theoretical views on strategic change, a focus on incremental change means significant changes in the research topic being pursued are relatively infrequent (Amburgey and Miner, 1992; Tushman and Romanelli, 1985).

There are a range of possible explanations as to why exploitation might lead to greater continuity in trajectory by publicly funded PIs. First, reflecting the central role of funding bodies, pressures to persist with past or existing strategies can stem from structural and political drivers, which may in turn influence the interpretations and research directions of PIs (Lant et al., 1992; Milliken and Lant, 1991). Second, the effort and time required to develop expertise around the "state of the art" can incentivise publicly funded PIs to persevere in that area and update their skill base rather than start from scratch in a different high-risk area. As stated by March (1991, p. 85), "the refinement and extension of existing 
competences, technologies, and paradigms are positive, proximate, and often predictable, thereby encouraging exploitation of existing research paths." In a study of creativity based on patenting in the hard disk drive industry, Audia and Goncalo (2007) offer further support for this view. They found that past success will see people generate new ideas that are less divergent given their preference for exploiting existing and proven domains. Third, consistent with Merton's (1965) notion of cumulativeness in science, PIs may persist with a certain trajectory, or incremental adjustments around it, to realise the benefits to accrue from enhanced reputation, legitimacy, and status (e.g., resource allocation, visibility). Hackett (2005), for instance, argues that the attractiveness of an area of study may be influenced by whether or not sufficient work can stem from it to build a durable identity among peers. Finally, disincentives for multiple changes in trajectory might be the complexity of sourcing and coordinating the necessary funds, instruments, techniques and teams of research (Franzoni et al., 2010) or the growing importance of visibility (Matthew effect) (Merton, 1968).

As pointed out in the strategy literature, when strategic changes do occur it is likely that they are in response to sustained periods of poor performance or a rational analysis of environmental conditions (Lant et al., 1992; Schendel and Hofer, 1979). Translated to the research activities of PIs in a competitively funded environment, this would indicate that such changes occur following a shift in the direction of funding allocations as a consequence of research and knowledge developments which devalue additional exploitation of the current research trajectory. As such, PIs need to remain alert and ensure they do not become complacent, inertial and fall victim to the perils of success (Miller, 1990; Salancik and Pfeffer, 1977). Their challenge is to both renew and persist with research 
efforts around an existing theme, and to respond to any changes in trajectory that do occur.

To continuously exploit and adapt in this manner, PIs must be flexible and reactive and open to dealing effectively with a multitude of internal and external stakeholders. As indicated in the strategy literature, a key facet of strategic flexibility is its tendency to adopt a broad field of view so that key opportunities and developments do not evade the strategist's attention (Doz and Kosonen, 2010; Shimizu and Hitt, 2004). To this end, we conceptualise PIs with more reactive strategic postures as nimble strategic actors with a broad field of vision who are constantly looking to exploit opportunities in both current and emerging research trajectories. While PIs with a reactive posture are less purposeful, in that the boundaries and trade-offs for selecting and shaping research projects are not strictly defined, the flexibility that allows them to react and exploit is a deliberate approach in itself.

\section{Research exploration and the proactive principal investigator}

Explorative research activities are more unconventional, original, innovative and untested. It involves reshaping the environment, changing traditional boundaries, and extended time horizons. Returns and outcomes, however, are less certain when experimenting with new alternatives. As explained by March (1991), the distance in time and space between learning and the locus for the realisation of returns is generally greater in the case of exploration than in the case of exploitation. Sensitivity to risk often means that exploration is likely to be less attractive to funding bodies and PIs alike. This is not surprising given that 
exploration improves less rapidly than exploitation (Levinthal and March, 1993;

March, 1991).

Exploratory research can involve serendipitous discoveries that open up new possibilities and areas of study (Austin, 1978; Bawden, 1986; Beveridge, 1980). It can be characterised by a vague general direction of inquiry, and it is anticipated that phenomena will emerge that warrant further consideration (Klahr and Simon, 1999; Simon 1973). It should also be noted that continuous improvements or refinements in research instruments, technology, algorithms or methodologies can spur high impact or transformational advancements in scientific discovery and understanding that may not yet be appreciated (Franzoni 2009; Luukkonen, 2012). In this respect, explorative research involves a certain degree of flexibility during implementation. As indicated in the strategy literature, flexibility during implementation requires continuous adaptation to unanticipated changes, and successful adjustment to the more surprising consequences of planned changes (Lei et al., 1996; Nadkarni and Narayanan, 2007). However, exploration will most often prevail when existing know-how or solutions are perceived as inadequate and in need of advancement or replacement. It involves PIs departing from an existing trajectory or set of activities that is no longer sufficient and exploring untested approaches. Once completed, exploitation of any exploratory success can again become the focus of attention. Thus explorative activities are associated with greater levels of proactive-ness and deliberate-ness. PIs will have a greater focus, passion and well thought out rationale as the boundaries and trade-offs for the selection and shaping of research projects are clearly defined. Again drawing on the strategy literature, and in particular the design school of thought, we conceptualise PIs with more proactive strategic postures as rational, (more) deliberate and purposeful actors (Mintzberg, 1990).

A second area of interest, when examining the strategic behaviours of PIs, is their perceptions of, and consequential approach to, funding applications for their research. Specifically, their perceived pressure or effort to conform to the expectations of funding agencies and public sector research organisations is likely to influence their strategic behaviours.

\section{Publicly funded research and principal investigator conformance}

The role of competitive and peer-reviewed public funding and its impact on research creativity and originality, and the career aspirations of scientists has received considerable empirical attention and critical commentary in the 
literature. It is argued that pressures from administrators and funding agencies are trumping creativity, undirected thinking and breakthroughs (Carlson, 2006; Loehle, 1990). Charlton (2009) claims that modern scientists are lacking ambition due to a science selection process that weeds out imaginative people and nimble, long-term and ambitious research, and instead engenders conscientious and agreeable people and slow moving, short-term and dull research. We conceptualise conformance as the degree to which PIs shape research projects to conform with funding agencies and public sector research organisations' expectations rather than prioritizing scientific ambition (scientific community). The influential role of stakeholders on the behaviours and goals of strategists has been acknowledged in the literature on stakeholder management (Ackermann and Eden, 2011).

Empirical studies support the view that the peer review funding system is largely risk-averse and hesitant in its support of speculative research proposals. In a study of the European Research Council, Luukkonen (2012) found that careful attention towards the control and management of risk in a decisionmaking process and an emphasis on current knowledge boundaries served to discourage controversial and truly innovative research. In an examination of institutional and organisational influences on creative research, Heinze et al. (2009) argued that peer reviewed funding did not support speculative and crossdisciplinary research ideas, and looked more favourably on predictable mainstream research. Laudel (2006) found that while competitively funded projects can guide research trajectories and quality, they also unintentionally encourage low-risk, conventional, applied, and inflexible research that often lacks quality and innovativeness, and discourage path-breaking projects. Bourke and 
Butler (1999) studied the impact of short-term (e.g., grants from the Australian Research Council) and stable long-term (e.g., secure employment contracts with research institutions) funding on the research activities and outputs of biological scientists in Australia. They found that scientists funded through the former engage in safer research with predictable outcomes, while those funded through the latter worked with more exploratory problems closer to the "state of the art"

The consequential perceptions arising from such peer review funding systems result in scientists becoming more risk-averse with their research proposals, and/or becoming unnecessarily despondent and prematurely dropping or altering potentially novel research directions (Berezin, 1998; Chubin and Hackett, 1990; Melin and Danell, 2006). According to Azoulay et al. (2011), greater attention should be afforded to the incentives inherent in research or funding contracts, as when designed appropriately they can heavily influence the rate and direction of scientific breakthroughs. Azoulay et al. (2011) found that funding programmes that reward long-term success, encourage experimentation, and provide rich as opposed to unforgiving feedback to applicants, lead to greater levels of novel and path breaking innovations. Their findings both support and are informed by Manso's (2011) modelling of the innovation process which argued that a tolerance for early failure and the rewarding of long-term success are essential to motivate exploration as they eliminate the fear of premature reprimands and termination by the principal, and motivate long-term commitment by the agent.

However, according to Heinze et al. (2009) funding bodies are burdened by tensions within their own evaluation criteria that mean they must balance scientific proposals based on plausibility, validation, and originality. It is 
suggested that plausibility and scientific validation promote conformity, while originality encourages dissent. We suspect scientists and PIs are cognisant of these same tensions when crafting their research projects. The extent to which they are influenced by pressures of conformance however, will vary. Previously productive PIs (as measured by publication counts, citation analysis, etc.) are less likely to be consumed by pressures of conformance. Possible explanations for this may include experience gains from previous research successes, a reputation for creativity or originality arising from productivity (Bozeman and Mangematin 2004; Simonton, 2004), and of course, consistent with Merton's (1968) “Matthew effect", improved confidence and effort accruing from the anticipated tendency for resource allocation, visibility and recognition to be substantiated further resulting in enlarged performance and profile differentials. As such, depending on their career stage, productivity and funding experience PIs will vary with respect to the weight they place on conformity in their funding or project applications.

Thus, publicly funded PIs operating in transitional environments face a challenging tension. Two key dimensions may help us understand the strategic behaviours of PIs in managing this tension, namely a more proactive or reactive strategic posture, and high or low levels of conformance in funding applications. Our review of the literature on exploitation/exploration; the design school of strategy; and the influence of peer review funding on research creativity provides some insights on how the characteristics of a research project can interact with the strategic behaviours of PIs. Specifically, the level of risk, processes of formation and implementation and the scope and horizon of a research project can differ depending on the degree of proactivity/reactivity and level of conformance of the PI. For example, it is likely that the originality of a particular 
research project will be higher for a PI whose strategic behaviour is epitomised by a proactive strategic posture and less pressure to conform in their funding applications. Table 1 provides a summary of how those research project characteristics identified interact with the strategic behaviours of PIs.

INSERT TABLE 1 HERE

\section{METHODOLOGY}

To examine the strategic behaviours of PIs, we focus on Ireland's publicly funded science (natural and agricultural), engineering and technology environment (universities, institutes of technology and public research centres). Irish PIs represent a suitable context for this study as the Irish government has been investing in Research since 2000. Prior to 2000, Irish public investment in SET was limited (€0.5 billion between 1994 and 1999), with researchers dependent on the EU Framework Programmes and other international funding sources to sustain research activities. The launch of such initiatives as the National Development Plan (2000-2006), the Programme for Research Innovation for Third Level Cycles (1-4), and the Strategy for Science Technology and Innovation (2006), saw a marked shift in national innovation policy. There followed substantial investment in physical and human capital to increase the scientific base to critical mass levels. For instance, a $€ 2.5$ billion investment in the area of STI lead to an increase of 33\% in publications across all disciplines between 1998 and 2007 (Forfás, 2010). Adding greater weight to the appropriateness of the subjects and context of this study, the Irish government also specified the intention to increase the number of research teams led by internationally 
competitive PIs. In 2008, Forfás, the state agency responsible for industrial policy

development, counted 264 PIs in Irish institutes of technology and 768 PIs in Irish universities in a population of 6,174 researchers (Forfás, 2008).

Ontologically, a qualitative research approach was deemed most appropriate, given the range of subjective realities that could exist when examining the strategic behaviours of PIs in a transitional and complex funding environment. We utilised a grounded theory approach (Strauss and Corbin, 1998) as existing theories proved inadequate in explaining the phenomenon that is PI strategising. Interviewing thirty PIs leading recently completed and on-going publicly funded research projects provided in-depth data from multiple instances of the phenomenon that was then compared and contrasted to provide unique insights on the strategic behaviours of publicly funded PIs. As detailed in the sections to follow, a number of measures were taken to improve the rigour of our research approach. First, validity was enhanced through the triangulation of data sources to incorporate different perspectives. Furthermore, interview transcripts were verified and contextual details on each PI/project, as well as the sample selection process utilised, were made as transparent as possible. Finally, the reliability of our research benefitted from the archiving of research materials including interview transcripts, PI and project documentation, as well as emerging shorthand analytical notes on each of these.

\section{Data collection}

There were two key phases in data collection. The first involved compiling a dataset of publicly funded research projects in Ireland's science, engineering and technology sector over the last five years. This phase also involved identifying appropriate PIs within this sample for closer examination. Our primary selection criteria were that only multi-annual and collaborative (preferably with industry) research projects with a funding value over $€ 250,000$ were considered. We also purposefully utilised a selection of on-going and recently completed projects so that we were less reliant on the capacity of PIs to accurately recall the past (Miller et al., 1997). Such an approach would allow details and patterns pertaining to strategic behaviours to be identified through the retrospective accounts of PIs referring to completed projects, as well as a close up view of such details and 
patterns as they evolve over time, to be taken through the real-time inputs of PIs referring to on-going projects (Leonard-Barton, 1990). Furthermore, to gather a sufficiently holistic view of strategic behaviours we selected a final sample of thirty PIs who were cross-disciplined, -gendered, -aged, and at different levels in their career. Table 2 presents an overview of the publicly funded PIs and their respective projects that were examined.

In the interest of confidentiality all respondents were allocated a unique identifier based on their position/status and the nature of research they were involved in. For example "P1.T" referred to "professor one who was involved in research exploitation" (P2.E referred to professor two who was involved in research exploration). Our final sample of PIs included eleven professors, four research directors, four senior researchers, nine research leaders, one lecturer and one research officer. There were twenty-five males and five females; twenty were based in universities, five in institutes of technologies and five in state research centres. In terms of the projects, sixteen were national and fourteen international; sixteen involved research exploitation and fourteen were exploratory; seventeen were completed and thirteen were on-going; and the exact subject areas varied within the broader areas of natural and agricultural sciences, and engineering and technology. Classification of the nature of the project as "exploit" or "explore" required each PI to reason and reach agreement with the interviewee as to how their project best fitted one of the two definitions provided to them, as set out in the section "strategic postures of principal investigators" above. 
The second phase of data collection involved semi-structured interviews with each PI (approximately 90 minutes each). Semi-structured interviews were an appropriate instrument due to the depth of inquiry they can generate (Bell, 1984; Yin, 2004). The interview guide focused on four key areas pertaining to the PI's strategic behaviours - 1) the process and rationale for the project's formation; 2) their approach to applying for funding; 3) their expectations with respect to the project's broader impact (publications, technology transfer etc.); and 4) their approach to coordinating the project's implementation.

To ensure interviewees answered questions on their own strategic behaviours as a PI and not their personal tendencies or preferences, we clarified before and during each interview that the context of analysis was to be an on-going or recently completed project for which they were lead PI. To substantiate this point further, in the lead up to interviews we examined documentation relevant to both the $\mathrm{CV}$ of the PI and the project in question (e.g., press releases, interim reports, final reports and workshop brochures, publication listings, patent listings etc.). This ensured that we were appropriately briefed and could direct the conversation accordingly. Notifying PIs of our intention to prepare in this manner also helped to focus the direction of their attention in advance of these interviews. We also asked for certain answers offered during interviews to be illustrated with examples from the project in question. The latter tactic was employed quite regularly to control for the fact that PIs rarely operate in isolation and as such, might be tempted to give answers that reflected the thought processes or outputs that naturally occur during research collaboration. It was imperative that 
interviewees were reminded that their own strategic behaviours were the subject of study. Finally, interviewees were encouraged to speak openly and freely. In return, they were informed that they would be assigned pseudonyms, could view and correct interview transcripts and that their confidentially would be guaranteed throughout our study and after its completion.

Thirty interviews, amounting to just over 400 pages in transcripts, was deemed an appropriate amount and indeed repetition in the final few interviews certainly suggested a saturation point had been reached. All interviews were transcribed, peer reviewed by project members and sent back to interviewees for confirmation. Adjustments and clarifications were made by twenty-eight of the PIs reflecting the sensitivity and highly confidential nature of their contributions.

\section{Data analysis}

Analysis of the data overlapped with earlier periods of data collection with preliminary impressions and patterns on the strategic behaviours of PIs being recorded in the form of shorthand notes during interviews (Miles and Huberman, 1994). These were combined with additional summary notes that had been compiled from the aforementioned project and PI documentation. Together these thirty shorthand documents were used to contextualise and support/challenge the coded data.

Consistent with grounded theory, our analysis utilised a number of levels of coding and integration (Strauss and Corbin, 1998). Interview transcripts were first coded for evidence of strategic posture and funding approach. Given the effort made to keep interviews focused on these areas, this process resulted in substantial amounts of high-level data. A second round of coding (axial coding) 
drilled deeper and segmented the data based on PIs' levels of pro/re-activeness with respect to their research project, and levels of conformance with respect to funding applications. In line with our clear construct development and definitions, we specifically looked for PI attention towards a number of sub-themes for each dimension. For instance, in terms of strategic posture, those PIs who frequently or heavily referred to refinement, risk-averseness, short-termism, flexibility, openness, and/or a deliberate intention to exploit a specific trajectory were categorised as more reactive. Those PIs who clearly emphasised originality, risk, long-termism, careful planning but flexibility in project implementation, and a clear purpose and passion for their research project were categorised as more proactive. In terms of conformance, high conformance was associated with those who primarily focused on the pressures and difficulty of securing funding, the need for relatively predictable outcomes and how the expectations of funding bodies needed to be prioritised. In contrast, low conformance was typified by those PIs who prioritised unconventional research with less clear outcomes over funding body expectations, and who referred to their tendency to leverage their own status, profile and productivity in funding applications.

Following this stage of coding and analysis, the data were arranged in four groupings - more proactive strategic posture; more reactive strategic posture; low funding conformance; high funding conformance. A third stage of selective coding (Strauss and Corbin, 1998) was used to compare, contrast and integrate the PIs (through their unique identifiers) in each grouping. This process revealed that those PIs most prominent in both the more proactive and more reactive groupings could be divided into those that were either in the high or low funding conformance groupings, and vice versa. This process unearthed a holistic 
understanding of the relationship between the two higher-level organising categories - strategic posture and funding conformance. This "relationship" takes the form of a matrix that organises the strategic behaviour of PIs into four distinct categories - "research designers"; "research adapters"; "research supporters"; and "research pursuers". Figure 1 depicts these four categories. According to our analysis, the thirty PIs were positioned as follows: five research designers; twelve research adapters; seven research supporters; and six research pursuers.

INSERT FIGURE 1 HERE

FINDINGS

After examining the strategic posture of publicly funded PIs and how they are more proactive or reactive, and mapping that against their level of conformance in funding applications, four distinct categories of PI strategic behaviours became apparent. Each of these is now presented.

\section{Research designers}

Research designers are highly purposeful in their research activities. They have clearly focused research trajectories that they proactively pursue. As one professor commented "I have no problem changing your clothes to suit a particular project but not to lose your core. That core is you must have a strong idea of where you are going, where you want to go, and what you want to achieve" (P10.E). Research designers have challenging ambitions and longer-term intentions that cannot be accomplished through standalone projects. Consequently, deliberate planning and the continuous alignment of research activities formed a central component of these PIs' behavioural approach. For 
example, one PI pointed out "we have particular goals that we are trying to solve and they are bigger than any one project. I always use projects as stepping stones to solving a particular set of problems...everything has to be interwoven" (P8.E). This finding is further substantiated by the views of another PI of professorial status who commented "we are always challenging ourselves to see where exactly we are and what do we look like. That is most often the thing that focuses us which is crucial" (P11.E). Proactive PIs combine projects to develop their own trajectory and shape the scientific field.

Research designers have a distinct passion and commitment for what they want to achieve. Whilst it is acknowledged that, to a certain extent, all PIs have to tailor their research proposals to the wishes of the funding body in question, our findings indicate that research designers are more selective when deciding what funding opportunities they will pursue and how they will frame their proposals within these opportunities. Rather than fully conforming to the expectations of the funding body, these PIs are more concerned with the originality of their research and how compatible it is with their broader research agenda. This is exemplified by one professor who commented, "if we want to be successful in heading where we are trying to get to, we cannot waste our time solely on trying to get the money" (P8.E). It was also pointed out by another professor that "there are a lot of very good PIs with impressive ideas but they refrain as they don't want to do these within the framework or in the direction the funding agency are trying to push them" (P7.E). Following our analysis, five PIs are positioned within this category. They are professorial-level faculty involved in exploratory research, ambitioning to shape the field to make their name within the community. 


\section{Research adapters}

A second category of PIs had their strategic behaviour characterised by a more reactive approach, and a hesitation to overly commit to a focused or long-term research agenda. These PIs concentrated on set trajectories but also maintained a sufficiently broad research focus which enabled them to shift to emerging developments as required. For example, one professor pointed out - "part of the problem of trying to strategically plan out our projects for the next three years is that you get dragged a lot. It is hard to say, 'I want to work in this area' because you might not get funding or the time" (P3.T). Another professor commented "it would be nice to be able to say our research focus is only on a, b or c, however, you have to be some bit flexible, we have survived and prospered simply because we have taken this type of strategic view" (P2.E). Likewise, in referring to his research progress to date, after persisting with a particular trajectory, another PI remarked - "In hindsight you could look at a whole bunch of tactics we had and say 'that looked like a great strategy'” (R9.T). Our findings indicate that one of the reasons these PIs adopt a more reactive and broad focused approach is to ensure that they do not forgo any career and/or research opportunities. As one senior researcher remarked "you have to follow the technology and the direction of your field. You cannot ignore it because you know everyone else is going to adopt it in your field" (S4.T). Another research director explained - "when specifying strategic research directions you don't want to be too rigid. You want your people to drive the strategic direction, if you put someone into something that is already there they are restricted in what they can do" (D4.E).

Similar to "research designers", the strategic behaviours of "research adapters" were also characterised by less conformance when it came to funding or project 
applications. PIs in this category seemed well rehearsed and confident in their ability to impress their research intentions upon the funding bodies. As explained by one professor "you differentiate yourself as a manager in the proposal writing stage. You have to have the management experience in the lead in to know how to put together and sell the package strategically to the funding body" (P1.T). Similarly another professor commented "you have to think about what exactly the concept you are putting forward is and how it can be framed. Only after clarifying that can you decorate it with creative English and buzzwords" (P4.T). Following our analysis, twelve PIs who are varied both in professional ranking and research type are positioned within this category. These include five professors, two research directors, three senior researchers and two research leaders, with three quarters of these involved in research exploitation and four involved in exploratory research. Researchers in that category mostly play with the environment to adapt their trajectory.

\section{Research supporters}

Research supporters emerged as a category of PIs that, like research designers, were very deliberate in how they planned their research activities. They also had a clearly defined and longer-term research trajectory that they proactively pursued. This is exemplified by the views of one PI: "we only apply to the funding schemes that we really want rather than the ones that are simply just available" (R8.T). Similarly another PI commented "we want to build expertise and make a difference in our area over time. You could not do that if you were jumping around with funding. The most fundamental thing is who you are working with and the problem you are working on" (P9.E). 
Unlike research designers, however, research supporters placed greater weight on conformance than on originality or risk-taking to progress their research endeavours through funding applications. In that sense, they are not challenging existing trajectories but reinforcing them. A number of views illustrate this finding. For example, one PI suggested: "you have to read the call's instructions and use this as a template. To get to conduct the research you often have to make it fit" (L1.T). Similarly, a senior researcher commented "you deliberately frame what it is you believe in a way that answers the funding body's questions fully" (S2.E). In adopting this approach, however, it is most probable that research supporters compromised the originality of their focused and preferred research activities. For instance one PI made the point "while you have a problem you want to look at in an area you are passionate about, you need to make it look like you are solving it in a particular way to satisfy the wishes of the funders and reviewers" (R6.T). Moreover, another research supporter explained "it is crucial to get big industry names if possible on your application and then to make the proposal fit with their expertise. You have to do everything you can to make sure it is successful" (R5.T). Following our analysis, seven PI are positioned within this category. These include one professor, four research leaders, one lecturer and one senior researcher. Four of these were involved in research exploitation and three were involved in explorative research.

\section{Research pursuers}

Research pursuers are akin to opportunists, and a distinguishable strategic focus in terms of a research agenda with which they are associated is either absent or at least ill-defined. Instead, research pursuers let their research activities emerge 
within a broad based research focus. As explained by one PI - "in science you have some individual or sole traders who have to be highly tactical. They are not really part of the institution's strategic mission and every time smaller funding calls come up they have to try and grasp them" (P7.E). Fitting this reactive description PI remarked - "if I take a grandstand, well what if I don't get funded? I think science in general has this randomness about it. I don't think the plans that people use in business apply in science. It has to be based on flexibility" (R4.E). Similarly, another PI commented - "if there is a call that is someway related to what we are doing then we are encouraged to go for it rather than waiting around for something that was totally aligned with our expertise and then risk not getting it" (R7.T). Thus, research pursuers choose to engage in and persist with more shortterm oriented research activities that may bring about success rather than proactively attempting to uncover new trajectories. These views were further substantiated by another PI who explained - "we build our integrated story around the funding successes rather than defining rigidly what our core is and only applying for funding in that area" (D1.T).

Like research supporters, conformity was heavily pronounced in the funding efforts of research pursuers. Consequently, there was less emphasis on originality and more concern with slightly adjusted standardised or generic approaches that would satisfy the expectations of funding bodies. One PI, for example, explained "for the technology transfer sections in the proposals we would write the script as best we could, and to be honest you say what you think they will believe. It is not all lies but you must put the best foot forward" (R2.E). Another PI pointed out how a template and the recycling of material was regularly used in his funding applications - "we put together a system where we analysed all the past projects 
that were done in-house and all the scores so that members of staff could go into our depository and take what they wanted and tweak it as they wish" (R7.T). Following our analysis, six PIs are positioned within this category. These include two research directors, three research leaders and one research officer, with four of these involved in research exploitation and two undertaking explorative research. Table 3 provides an overview of the four PI strategic behaviour categories uncovered and how they applied to the study's respondents.

INSERT TABLE 3

\section{Categorisation profiles}

A secondary form of analysis was next undertaken to gain a fuller understanding of our four categories of strategic behaviours. We gathered measures relating to research performance and research funding award success. To determine whether PIs in the different strategic behaviour categories operated at different research performance levels, $h$-index and $m$-quotient measures were calculated using the ISI Thomson Scientific Web of Knowledge (Hirsch, 2005). The $h$-index combines an assessment of both quantity (number of papers) and quality (impact, or citations to these papers). Hirsch's caveat that "a single number can never give more than a rough approximation to an individual's multifaceted profile, and many other factors should be considered in combination in evaluating an individual" should also be noted. In the context of this study, an important limitation of the $h$-index is that it disadvantages less experienced faculty members whose papers have not had sufficient time to accumulate citations. Recognising this, Hirsch proposed that the $h$-index is divided by the number of years since the academic first published, referring to this as the $m$-quotient. An analysis of the 
patenting activity of the publicly funded PIs was also carried out, however, given the small sample size the only patterns appeared to relate patenting activity to individual institution IPR practices rather than any particular strategic behaviour on the part of the PIs.

In terms of funding awards, the dataset of publicly funded research projects in Ireland's science, engineering and technology sector over the last five years was used to generate a profile of the research project funding achievements of publicly funded PIs, and to carry out a portfolio assessment of their publicly funded research activity in terms of number of projects and scale of projects (as measured by median project award). Tables 4 and 5 present summary data on the research performance and research funding award success for each of our PI behaviour categories. It is important to point out that this secondary analysis played no part in the formation of the four strategic behaviour categories but rather provides a means to better understand the profiles of each.

INSERT TABLE 4 AND 5 HERE

Interestingly, this analysis revealed that research designers were the highest performers in terms of $h$-index and $m$-quotients values, as well as in median funding awards. We also note that they are the most experienced PIs in our sample, if we take year of first publication and median number of projects into account. This point is further supported by the fact that each of our research designers are of professorial status. Next highest in terms of our performance and funding criteria are research adapters. Notably they are also the second most experienced in terms first publication and median number of projects. Again, this 
point is somewhat supported by our findings which reveal that this category included five professors, two research directors, three senior researchers and two research leaders.

Research supporters and pursuers were the lowest performing PI categories with research supporters marginally outperforming research pursuers in terms of $h$-index and $m$-quotients values, as well as in median funding awards. Once again, it is interesting to note that they were somewhat more experienced than research pursuers in terms of year of first publication, median number of projects and the make-up of professional titles in each category (see table 3). Both categories, however, were similar in the manner by which they heavily conform to the expectations of funding bodies. As noted by one professorial PI, "some researchers put a lot of work into building their track record and to try and emerge stronger and to move up to the next level" (P7.B). While research supporters preferred to undertake deliberately formulated and focused research activities, research pursuers adopted an umbrella-like strategy, with loosely defined boundaries allowing their research activities to emerge in an opportunistic fashion (Mintzberg and Waters, 1985).

\section{DISCUSSION}

PIs act as strategists when they are designing publicly funded projects. In terms of scientific engagement, they must choose to reinforce a trajectory or explore a different one. In terms of stakeholder expectations, they must figure out how to secure their buy-in. Following our analysis, we find that the strategic behaviours of PIs fall into four specific categories. The categories are influenced by strategic posture and level of conformance in funding applications. These findings, together 
with the profile details within each category, raise a number of interesting points for discussion.

First, our study has identified four strategic behaviours that underlie the research activities of PIs in a publicly funded research environment. Specifically, we find that these strategic behaviours incorporate two predominant strategic postures. On one end of the continuum, there are those PIs with a more proactive posture who have a clear(er) research agenda and who focus on novel, groundbreaking and long-term research trajectories. On the other end, there are those PIs who have a broader and more emergent research agenda and who prefer to persist with existing trajectories and accumulate incremental advancements over shorter time horizons. These findings indicate that the strategic behaviours - at an individual level - resonate with theories of organisational learning (March, 1991). While the relationship between proactive and reactive postures and research exploitation and exploration is not completely conclusive, it is substantially supported in our findings. Specifically, two thirds of our more reactive PIs are involved in research exploitation $(12 / 18)$ and the same proportion of our more proactive PIs are involved in research exploration (8/12). Pro- and re-active PIs interact with their environment in different ways. While reactive PIs concentrate on adapting, and in so doing pursue and/or deepen existing trajectories, proactive PIs enact their environment. Research projects underpinned by a more proactive posture are characterised by greater levels of risk, and can shape new research trajectories as well as future funding programmes. These findings therefore support the notion that strategy making involves both rigorous planning together with imagination or efforts to think outside the box (Szulanski and Amin, 2001).

Our second point of note discusses the significance of these strategic behaviours for resource allocation by funding bodies and policy makers. An appreciation of the different behaviour categories is an important consideration in such decisions as they provide an insight into the competitive dynamics and challenges present in a publicly funded research environment. To ensure there is an appropriate balance of research exploration and exploitation, policy makers need to provide funding schemes that facilitate PIs to undertake research activities that fit with the different strategic postures uncovered in this study.

It has been argued that funding bodies and their peer review mechanisms can stifle exciting, novel and highly original research endeavours (Heinze et al., 2009; Luukkonen, 2012). Furthermore, Azoulay et al. (2011) point out that the policies 
and funding processes traditionally used by international research agencies (e.g., the National Institute of Health and the European Union Framework Programs) have been criticised for over emphasising the importance of track records, or for imposing structured research frameworks on PIs. The strategic behaviour categories uncovered here help to emphasise the interplay between strategic actors and selection mechanisms. Strategic decisions under strong conformation mechanisms serve to discourage the type of risk-taking that can lead to new trajectories. The challenge for funding bodies and policy makers is to ensure that there are sufficient opportunities for more proactive PIs. Moreover, resources for exploratory research should not be only attainable by the most experienced and eminent PIs. Audia and Goncola (2007), for instance, argue that allocating resources predominantly to prolific inventors may increase the creative output but it may lessen the extent to which the creative output reflects exploratory efforts. We concur with this view and argue that insufficient resource provision for exploratory research will result in research designers and supporters becoming even more reactive as strategic agents, or at the very least less proactive. This may result in a decrease in the quantity and/or quality of longterm exploratory research by publicly funded PIs. As pointed out by March (1991), success is a key reason why exploitation often drives out exploration.

Our recommendations are not solely directed at exploratory research, however, they seem more critical at this juncture given Laudel's (2006, p. 503) view that the forces of exploitation are strengthened by funding structures that systematically discourage "playful" research, and that the exploration of new alternatives and paradigms might become "endangered species" in science. We recommend that similar attention is afforded to the balance of resources and 
funding opportunities provided to more reactive PIs. Incremental advancements in knowledge and science, as well as more certain returns on investment, are equally imperative to the upkeep and sustainability of a publicly funded research environment. Thus, the strategic behaviours of PIs uncovered in this study are a valuable consideration for funding bodies and policy makers when allocating resources and formulating funding calls that can deliver an appropriately balanced proportion of research exploration and exploitation. Understanding the strategic postures of publicly funded PIs is also valuable to university administrations and research support teams who often have limited central organisational resources to support their researchers.

Our third point of discussion relates to the careers and performance expectations of PIs. According to Heinze (2008), little is known about how funding mechanisms affect scientists' research strategies. Our findings suggest that pressures to conform are compromising research originality amongst less experienced PIs and if left ignored may lead to greater homogeneity in the strategic postures of research pursuers and research supporters. Consider, for instance, the significant performance differentials between research designers/adapters and research supporters/pursuers. Comparably, the latter categories are less experienced in terms of year of first publication, funding success and projects, as well as (on average) professional title. While it is natural that less senior or established staff will not be as successful as their more senior counterparts, our findings suggest that this lack of experience heavily influences the strategic behaviours of PIs. Less senior or accomplished faculty are continuously pressurised and disproportionally concerned with writing proposals in attempts to secure funding (Carlson, 2006). We find that these efforts are 
characterised by high levels of conformity in their funding applications. For research pursuers this further substantiates their ill-defined research agenda, while for research supporters it compromises their preference to undertake explorative or unconventional research activities. This may result in greater uniformity in the strategic postures of less experienced PIs.

Our findings indicate that with experience and past success, PIs become more selective, confident and utilise less conformity in their funding approach. This finding is consistent with life cycle theories that suggest that less experienced researchers tend to concentrate on building reputation in academia and then later in their careers they look to capitalise on the expertise they have developed across of variety of stakeholder groups (Stephan and Levin, 1992; Zuckerman and Merton, 1972).Moreover, Laudel (2006) argues that excellent scientists can choose between funding sources rather than change their research direction. While it is acknowledged that each of our PIs have already had some funding/project success, it is important that PIs, funding bodies and university management alike recognise how higher levels of conformity influence the strategic behaviours of (less experienced) PIs. Overlooking these findings may result in a level of disenchantment among promising PIs, stagnating career progression, and the dropping or redirecting of exciting research proposals that progress new scientific discovery and knowledge. With this in mind, we agree that it is important to identify different types of researchers and their level of performance, and that possibly all researchers should not be concentrating on the same performance objectives (Larsen, 2011). 


\section{CONCLUSION}

Our results shed light on the heretofore neglected strategic behaviours underlying the research activities of publicly funded PIs. We make a number of significant contributions to the strategy and research policy literatures. Most fundamentally, in uncovering four distinct strategic behaviour categories and the importance of strategy to public policy and the management of publicly funded research projects, we have embraced the need to carry out strategy research across different literatures. (Floyd et al., 2011). In so doing, we emphasise how competitive actors deal with conformance pressures and strategise in transition and uncertain environments. Furthermore, the findings indicate that the strategic behaviours of PIs, in a competitively functioning public research environment, resonate with our broader theoretical understanding of organisational evolution and learning. Specifically, our strategic behaviours emphasise the importance of balancing research activities characterised by effective selection, adaptation and exploitation with those promoting variation, exploration and the generation of novel research combinations (Hannan and Freeman, 1977; Levitt and March, 1988; Lumsden and Singh, 1990; March, 1991).

Our findings also have a number of important implications for policy makers, the practicing PI and indeed strategists. First, we find that the strategic behaviours of PIs fall into four categories - research designer; research adapter; research supporter and research pursuer - and that these categories are influenced by strategic posture and conformance. While more reactive PIs concentrate on a strategy of adaptation, more proactive PIs look to enact their environment. Practicing PIs need to reflect on which posture or category best characterises their own strategic behaviours and how they can either prolong, or progress from, this positioning. Second, funding bodies and policy makers must recognise that the selection mechanisms of research strategies are interwoven with the pro-reactive posture of strategic actors as well as their degree of conformance. When the selection mechanism is based on conformance, it discourages proactive exploration strategies and encourages conformity. Moreover, resource allocation must promote an appropriate balance of research exploration and research exploitation activities. Failure to do do so may result in an imbalanced publicly funded research portfolio that is dominated by short-term 
incremental-oriented research at the expense of creative, exciting and novel research trajectories. Ultimately, the rate and quality of scientific discovery could be compromised. Finally, to fully engender and service the different type of strategic actors within a publicly funded research environment, policy makers and funding bodies need to be aware of how publicly funded PIs perceive and treat funding opportunities. While established and accomplished PIs can be more adept and selective in this regard, pressures to conform among less experienced PIs heavily influences their strategic behaviours and may lead to greater homogeneity in their strategic postures and types of research. If not attended to this could result in reduced effort, redirection of promising research and even career exits from those frustrated with unattractive or stagnating career paths. In essence, it has implications for the future direction of scientific discovery that underpins our economic and social progress.

\section{Limitations and future research}

It should be noted that the behaviour categories presented do not necessarily suggest that certain PIs are better strategists than others, but merely that they strategise in different ways, where there is broad commonality in the process and practices that are required to compete and acquire public funding. Our research, of course, is not without its limitations. First, we gathered (cross section) data from Ireland's STI sector on this exciting area of study. Though a promising beginning, it would be beneficial to extend the study within the sector chosen and also across disciplines and national research environments. Second, as alluded to in our method, it would be interesting to expand our analysis and see if the strategic behaviours of PIs vary from project to project, or how they are 
influenced by different research collaborations. In relation to the former specifically; while we believe that the projects we based each of our PI discussions around represent proxies for their broader research agenda, it is acknowledged that a PI could be more proactive or explorative in their research agenda but exploiting in one particular project. We therefore encourage future researchers to delve deeper and to focus on PIs' broader research agendas when examining their strategic behaviours. Finally, while PI position, experience and nature of research were incorporated here to categorise strategic behaviours, more detailed profile analysis may provide a fruitful line of inquiry in future studies. Specifically, the measures utilised in our secondary analysis to present a categorisation of the behaviour profiles (e.g., $h$-index; number of projects; funding amount) could be utilised as input measures that affect the type of strategic behaviours. This suggestion is consistent with those in the literature on public policy who have called for greater attention to be afforded to other factors such as age, stage of the life cycle, tenure status, gender, institution and field of training, and sources and amounts of funding when examining research profiles (Larsen, 2011; Thursby and Thursby, 2011).

\section{References}

Ackermann, F., Eden, C., 2011. Strategic management of stakeholders: Theory and practice. Long Range Planning 44 (3), 179-196.

Adler, N., Elmquist, M., Norrgren, F., 2009. The challenge of managing boundaryspanning research activities: Experiences from the Swedish context. Research Policy38 (7), 1136-1149. 
Amburgey, T.L., Miner, A.S., 1992. Strategic momentum: the effects of repetitive, positional and contextual momentum on merger activity. Strategic Management Journal 13, 335-348.

Audia, P., Goncalo, J., 2007. Past success and creativity over time: A study of inventors in the hard disk drive industry. Management Science 53 (1),115.

Austin, J.H., 1978. Chase, Chance, and Creativity. The Lucky Art of Novelty. Columbia University Press, New York.

Azoulay, P., Manso, G., Zivin, J.G., 2011. Incentives and creativity: evidence from the academic life sciences. RAND Journal of Economics 42 (3), 527-554.

Bawden, D., 1986. Information systems and the stimulation of creativity. Journal of Information Science12, 203-216.

Bell, J., 1984. Doing your Research Project. Open University Press, Milton Keynes. Berezin, A., 1998. The perils of centralized research funding systems. Knowledge, Technology \& Policy11 (3), 5-26.

Beveridge, W.I.B., 1980. Seeds of Discovery. Heinemann, London.

Bozeman, B., Mangematin, V., 2004. Editor's introduction: scientific and technical human capital. Research Policy 33 (4), 565-568.

Bourgeois, L.J., 1980. Strategy and environment: a conceptual integration. Academy of Management Review 5 (1), 25-39.

Bourke, P., Butler, L., 1999. The efficacy of different modes of funding research: perspectives from Australian data on the biological sciences. Research Policy 28 (5), 489-499.

Carlson, T.N., 2006. Deficiencies in the present funding process in meteorology. Bulletin of the American Meteorological Society87, 567-570. 
Casati A., Genet, C., 2013. Principal investigators as scientific entrepreneurs. The Journal of Technology Transfer, Online First, Available at: http://link.springer.com/content/pdf/10.1007\%2Fs10961-012-92756Charlton, B.G., 2009. Why are modern scientists so dull? How science selects for perseverance and sociability at the expense of intelligence and creativity. Medical Hypotheses 72 (3), 237-243.

Chubin, D.E., Hackett, E.J., 1990. Peerless Science: Peer Review and U.S. Science Policy. SUNY Press, New York.

Cunningham, J., O'Reilly, P., O'Kane, C., Mangematin, V., 2013. The inhibiting factors that principal investigators experience in leading publicly funded research projects. The Journal of Technology Transfer, Online First, Available at: http://link.springer.com/content/pdf/10.1007\%2Fs10961$\underline{012-9269-4}$

Doz, Y.L., Kosonen, M., 2010. Embedding strategic agility: a leadership agenda for accelerating business model renewal. Long Range Planning 43, 370-382.

Fisher, R.L., 2005. The Research Productivity of Scientists: How Gender, Organization Culture and the Problem Choice Process Influence the Productivity of Scientists. University Press of America, Lanham, Maryland. Floyd, S.W., Cornelissen, J.P., Wright, M., Delios, A., 2011. Processes and practices of strategizing and organizing: review, development, and the role of bridging constructs. Journal of Management Studies 48 (5), 933-952.

Forfás, 2010. Profile of Public Research Activity in Ireland 1998-2006. Forfas and Higher Education Authority, Dublin, Available at: http://www.forfas.ie/publication/search.jsp?ft=/publications/2010/title, 7199,en.php. 
Forfás, 2008.Forfás Higher Education Research and Development Survey Report (2008), Forfas and Higher Education Authority, Dublin, Available at: www.forfas.ie/media/forfas101223-HERD 2008.pdf.

Franzoni, C., 2009. Do scientists get fundamental research ideas by solving practical problems? Industrial and Corporate Change 18, 671-699.

Franzoni, C., Simpkins, C.L., Li, B., Ram, A., 2010. Using content analysis to investigate the research paths chosen by scientists over time. Scientometrics 83 (1), 321-335.

Hackett, E.J., 2005. Essential tensions: identity, control, and risk in research. Social Studies of Science 35 (5), 787-826.

Hannan, M.T., Freeman, J.H., 1977. The population ecology of organizations. American Journal of Sociology 82, 929-964.

Heinze, T., 2008. How to sponsor ground-breaking research: a comparison of funding schemes. Science and Public Policy 35, 302-318.

Heinze, T., Shapira, P., Rogers, J.D., Senker, J.M., 2009. Organizational and institutional influences on creativity in scientific research. Research Policy $38,610-623$.

Hirsch, J.E., 2005. An index to quantify an individual's scientific research output. Proceedings of the National Academy of Sciences of the United States of America 102 (46), 16569-16572.

Jarratt, D., Stiles, D., 2010. How methodologies and tolls framing managers. Strategizing Practice in Competitive Strategy Development 21 (1), 28-43. Kidwell, D.K., 2013. Principal investigators as knowledge brokers: amultiple case study of the creative actions of PIs in entrepreneurial science. Technological Forecasting and Social Change 80, 212-220. 
Klahr, D., Simon, H.A., 1999. Studies in scientific discovery: complementary approaches and convergent findings. Psychological Bulletin125 (5), 524543.

Lant, T.K., Milliken, F.J., Batra, B., 1992. The role of managerial learning and interpretation in strategic persistence and reorientation: an empirical exploration. Strategic Management Journal 13, 585-608.

Larsen, M.T., 2011. The implications of academic enterprise for public science: an overview of the empirical evidence. Research Policy 40 (1), 6-19.

Laudel, G., 2006. The art of getting funded: how scientists adapt to their funding conditions. Science and Public Policy 33 (7), 489-504.

Lei, D., Hitt, M.A., Goldhar, J.D., 1996. Advanced manufacturing technology: organizational design and strategic flexibility. Organization Studies17, 501-523.

Leonard-Barton, D., 1990. A dual methodology for case studies: synergistic use of a longitudinal single site with replicated multiple sites. Organization Science1, 1-19.

Levinthal, D.A., March, J.G., 1993. The myopia of learning. Strategic Management Journal 14, 95-112.

Levitt, B., March, J.G., 1988. Organizational learning. Annual Review of Sociology $14,319-340$.

Loehle, C., 1990. A guide to increased creativity in research: inspiration or perspiration? BioScience 40 (2), 123-129.

Lumsden, C.J., Singh, J.V., 1990. The dynamics of organizational speciation, in: Singh, J.V. (Ed.), Organizational Evolution: New Directions. Sage, Newbury Park CA, pp. 145-163. 
Luukkonen, T., 2012. Conservatism and risk taking in peer review: emerging ERC practices. Research Evaluation 21, 48-60.

Mangematin, V., O'Reilly, P., Cunningham, J., 2013. Principal investigators as boundary spanners, science and market shapers. The Journal of Technology Transfer, Online First, Available at: http://link.springer.com/content/pdf/10.1007\%2Fs10961-012-9270-y

Manso, G., 2011. Motivating innovation. Journal of Finance66, 1823-186.

March, J.G., 1991. Exploration and exploitation in organizational learning. Organization Science2 (1), 71-87.

Melin, G., Danell, R., 2006. The top eight percent: development of approved and rejected applicants for a prestigious grant in Sweden. Science and Public Policy 33 (10), 702-712.

Merton, R.K., 1965. On the Shoulders of Giants: A Shandean Postscript. Free Press, New York.

Merton, R.K., 1968. The Matthew effect in science. Science 159 (3810), 56-63.

Miles, M.B., Huberman, A.M., 1984. Qualitative Data Analysis: A Source Book of New Methods. Sage, Beverly Hills, CA.

Miller, C.C., Cardinal, L.B., Glick, W.H., 1997. Retrospective reports in organizational research: a reexamination of recent evidence. Academy of Management Journal 40, 189-204.

Miller, D., 1990. Organizational configurations: cohesion, change and prediction. Human Relations 43, 771-789.

Milliken, F.J., Lant, T.K., 1991. The impact of an organization's recent performance history on strategic persistence and change, in: Shrivastava, P., Huff, A., 
Dutton, J. (Eds.), Advances in Strategic Management, vol. 7. JAI Press: Greenwich, CT, pp.129-156.

Mintzberg, H., 1990. The design school: reconsidering the basic premise of strategic management 11 (3), 171-195.

Mintzberg, H., Waters, J.A., 1985. Of strategies deliberate and emergent. Strategic Management Journal 6 (3), 257-272.

Morris, N., Rip, A., 2006. Scientists' coping strategies in an evolving research system: the case of life scientists in the UK. Science and Public Policy 33 (4), 253-263.

Nadkarni, S., Narayanan, V.K., 2007. Strategic schemas, strategic flexibility, and firm performance: the moderating role of industry clock speed. Strategic Management Journal 28, 243-270.

Porac, J.F., Wade, J.B., Fischer, H.M., Brown, J., Kanfer, A., Bowker, G., 2004. Human capital heterogeneity, collaborative relationships, and publication patterns in a multidisciplinary scientific alliance: a comparative case study of two scientific teams. Research Policy33 (4), 661-678.

Prieto, L.C., 2010. Proactive personality and entrepreneurial leadership: exploring the moderating role of organizational identification and political skill. Academy of Entrepreneurship Journal 16, 107-121.

Quinn, J.B., (1995). Strategies for change, in: Mintzberg, H., Quinn, J.B., Voyer, J. (Eds.), The Strategy Process. Prentice-Hall, Englewood Cliffs, NJ.

Randall, K.R., Resick, C.J., DeChurch, L.A., 2011. Building team adaptive capacity: the roles of sensegiving and team composition. Journal of Applied Psychology 96, 525-540. 
Salancik, G.R., Pfeffer, J., 1977. Constraints on administrative discretion: the limited influence of mayors on city budgets. Urban Affairs Quarterly 12, 475-498.

Schendel, D., Hofer, C., (Eds.), 1979. Strategic Management. Little-Brown, Boston, MA.

Shimizu, K., Hitt, M.A., 2004. Strategic flexibility: organizational preparedness to reverse ineffective strategic decisions. Academy of Management Executive $18(4), 44-59$.

Simon, H.A., 1973. Does scientific discovery have a logic? Philosophy of Science $40,471-480$.

Simonton, D.K., 2004. Creativity in Science: Chance, Logic, Genius, and Zeitgeist. Cambridge University Press, Cambridge.

Simpson, B., Powell, M., 1999. Designing research organizations for science innovation. Long Range Planning 32 (4), 441-45.

Smart, C., Vertinsky, I., 1984. Strategy and the environment: a study of corporate responses to crisis. Strategic Management Journal 5 (3), 199-213.

Smith, W.K., Binns, A., Tushman. M.L., 2010. Complex business models: managing strategic paradoxes simultaneously. Long Range Planning43 (2/3), 448461.

Stephan P.E., Levin, S.G., 1992. Striking the Mother Lode in Science: The Importance of Age, Place and Time. Oxford University Press, Oxford.

Strauss, A., Corbin, J., 1998. Basics of Qualitative Research: Techniques and Procedures for Developing Grounded Theory. Sage: Thousand Oaks, CA.

Szulanski, G., Amin, K., 2001. Learning to make strategy: balancing discipline and imagination. Long Range Planning 34, 537-556.

Thursby, J.G., Thursby, M.C., 2011. Faculty participation in licensing: implications for research. Research Policy 40 (1), 20-29. 
Tushman, M., Romanelli, E., 1985. Organizational evolution: a metamorphosis model of convergence and reorientation, in: Cummings, L.L., Staw, B.M. (Eds.), Research in Organizational Behavior, vol. 7. JAI Press, Greenwich CT, pp.171-222.

Yin, R.K., 2004. The Case Study Anthology. Sage, Thousand Oaks.

Zuckerman, H., Cole, J.R., 1994. Rearch strategies in science: a preliminary inquiry. Creativity Research Journal 7, 391-405.

Zuckerman, H, Merton, R.K., 1972. Age, aging, and age structure in science, in: Riley, M.W., Johnson, M., Foner, A. (Eds.), Aging and Society: Vol: 3, A Sociology of Age Stratification. Sage Foundation, New York, pp. 292-356. 


\section{Tables and Figures}

\section{Figure 1 - Principal investigator strategic behaviour categories}

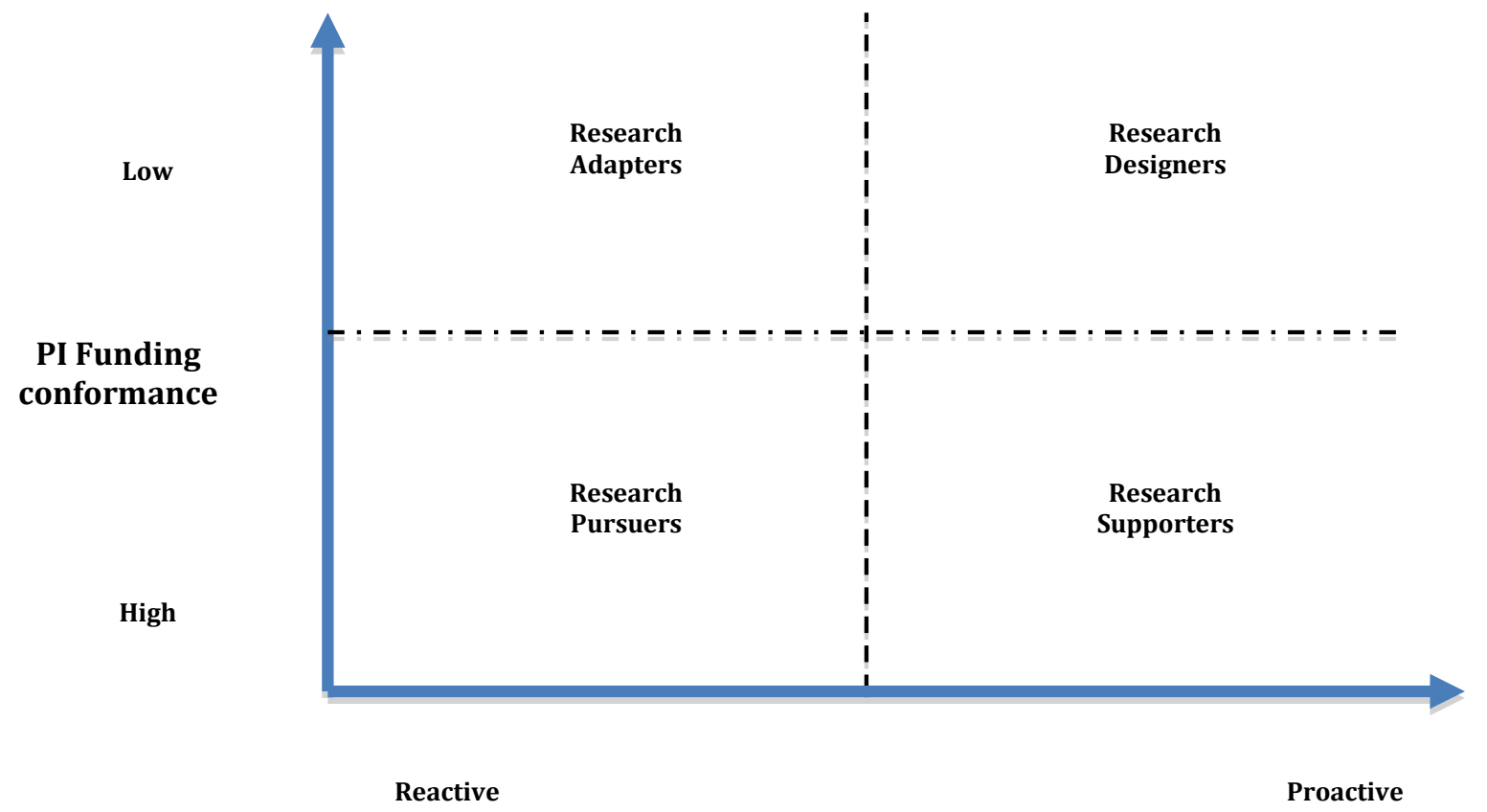

PI strategic posture

Table 1: Summary of research project characteristics and principal investigator strategic behaviours

\begin{tabular}{|l|cccc|}
\hline \multirow{2}{*}{$\begin{array}{l}\text { Research Project } \\
\text { Characteristics }\end{array}$} & \multicolumn{2}{|c|}{ Strategic Behaviour of Publicly Funded Principal Investigators } \\
\cline { 2 - 5 } & \multicolumn{2}{|c|}{ Strategic posture } & \multicolumn{2}{c|}{ Level of conformity } \\
& Proactive & Reactive & Low & High \\
\hline Originality/risk & High & Medium to low & Medium to high & Low \\
Formation & Deliberate & Emergent & Deliberate & Emergent \\
Implementation & Flexible & Persistent & - & - \\
Scope & Focused & Broad & Narrow to broad & Broad \\
Horizon & Long-term & Short-term & Short/Long-term & Mainly short-term \\
\hline
\end{tabular}


Table 2 - Overview of principal investigator interviews

\begin{tabular}{|c|c|c|c|c|c|c|c|c|c|}
\hline \multicolumn{4}{|c|}{ Principal Investigator Details } & \multicolumn{6}{|c|}{ Project Details } \\
\hline I.D. & Gender & Title & Institution & Research Area & Focus & Partners & Nature & Status & Project Value \\
\hline P1.T & Male & Research Coordinator, Dr. & University & Life Sciences & National & 6 & Exploit & On-going & $€ 3 \mathrm{~m}-€ 5 \mathrm{~m}$ \\
\hline O1.T & Female & Research Officer, MBA & State Research Centre & Life Sciences & National & 9 & Exploit & On-going & $€ 500,000-€ 1 \mathrm{~m}$ \\
\hline R1.E & Male & Research Leaders, Dr. & State Research Centre & Life Sciences & National & 2 & Explore & Completed & $€ 200,000-€ 500,000$ \\
\hline R2.E & Male & Research Leader, Dr. & State Research Centre & Life Sciences & National & 3 & Explore & Completed & $€ 200,000-€ 500,000$ \\
\hline R3.E & Female & Head of Dept, Dr & State Research Centre & Life Sciences & National & 6 & Explore & Completed & $€ 3 \mathrm{~m}-€ 5 \mathrm{~m}$ \\
\hline R4.E & Female & Research Leader, Dr. & State Research Centre & Life Sciences & International & 9 & Explore & Completed & $€ 500,000-€ 1 \mathrm{~m}$ \\
\hline P2.E & Male & Professor & University & Life Sciences & International & 12 & Explore & Completed & $€ 500,000-€ 1 \mathrm{~m}$ \\
\hline R5.T & Male & Research Leader, Dr. & University & ICT & National & 2 & Exploit & On-going & $€ 200,000-€ 500,000$ \\
\hline P3.T & Male & Professor & University & ICT & International & 2 & Exploit & On-going & $€ 200,000-€ 500,000$ \\
\hline R6.T & Male & Research leader, Dr. & University & ICT & International & 10 & Exploit & Completed & $€ 1 \mathrm{~m}-€ 2 \mathrm{~m}$ \\
\hline R7.T & Male & Research Leader, Dr. & Institute of Technology & ICT & International & 10 & Exploit & Completed & $€ 200,000-€ 500,000$ \\
\hline D1.T & Male & Executive Director & Institute of Technology & ICT & National & 2 & Exploit & Completed & $€ 200,000-€ 500,000$ \\
\hline $\mathrm{D} 2 . \mathrm{T}$ & Male & Executive Research Director, Dr. & Institute of Technology & ICT & International & 5 & Exploit & Completed & $€ 500,000-€ 1 \mathrm{~m}$ \\
\hline P4.T & Male & Professor & Institute of Technology & ICT & National & 2 & Exploit & Completed & $€ 200,000-€ 500,000$ \\
\hline P5.T & Male & Deputy Research Director, Prof. & University & Physics & International & 3 & Exploit & On-going & $€ 200,000-€ 500,000$ \\
\hline S1.E & Female & Senior Researcher, Dr & University & Physics & National & 3 & Explore & On-going & $€ 200,000-€ 500,000$ \\
\hline S2.E & Male & Senior Researcher, Dr. & University & Physics & National & 2 & Explore & On-going & $€ 200,000-€ 500,000$ \\
\hline P6.E & Male & Professor & University & Physics & National & 2 & Explore & Completed & $€ 100,000-€ 200,000$ \\
\hline P7.E & Male & Professor & University & Physics & National & 2 & Explore & Completed & $€ 500,000-€ 1 \mathrm{~m}$ \\
\hline P8.E & Male & Research Centre Director, Prof & University & Chemistry & International & 11 & Explore & On-going & $€ 500,000-€ 1 \mathrm{~m}$ \\
\hline R8.T & Male & Research Leader, Dr. & University & Chemistry & International & 7 & Exploit & On-going & $€ 200,000-€ 500,000$ \\
\hline L1.T & Male & Lecturer, Dr. & University & Chemistry & National & 2 & Exploit & On-going & $€ 200,000-€ 500,000$ \\
\hline P9.E & Male & Professor & University & Life Sciences & International & 9 & Explore & Completed & $€ 500,000-€ 1 \mathrm{~m}$ \\
\hline P10.E & Male & Professor & University & Biotechnology & International & 3 & Explore & On-going & $€ 200,000-€ 500,000$ \\
\hline S3.T & Female & Senior Researcher & University & Biotechnology & International & 4 & Exploit & Completed & $€ 200,000-€ 500,000$ \\
\hline D3.T & Male & Executive Research Director, Dr. & University & Engineering & National & 2 & Exploit & Completed & $€ 200,000-€ 500,000$ \\
\hline P11.E & Male & Professor & Institute of Technology & Engineering & National & 3 & Explore & Completed & $€ 500,000-€ 1 \mathrm{~m}$ \\
\hline S4.T & Male & Senior Researcher, Dr. & University & Engineering & International & 5 & Exploit & On-going & $€ 500,000-€ 1 \mathrm{~m}$ \\
\hline D4.E & Male & Executive Research Director, Dr. & University & Engineering & International & 2 & Explore & Completed & $€ 200,000-€ 500,000$ \\
\hline R9.T & Male & Research Leader, Dr. & Institute of Technology & Engineering & National & 2 & Exploit & On-going & $€ 500,000-€ 1 \mathrm{~m}$ \\
\hline
\end{tabular}


Table 3 - Overview of principal investigator strategic behaviour categories

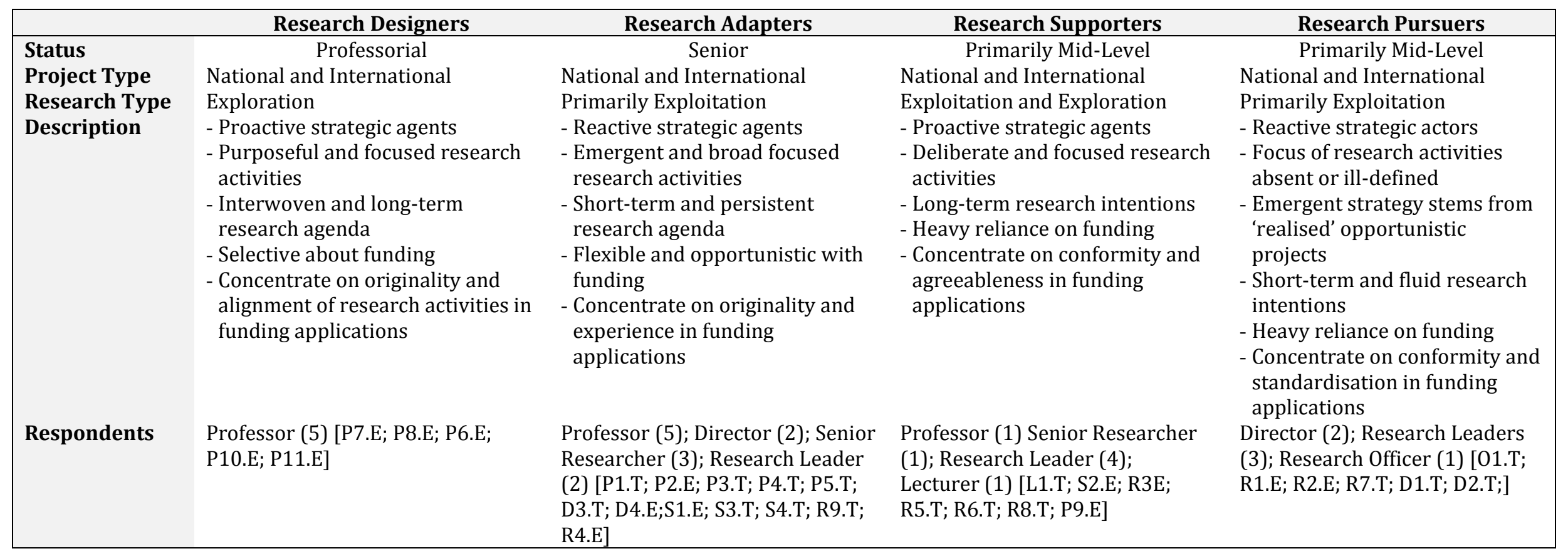


Table 4 - Summary of median $\mathrm{h}$-index and m-quotient scores for each principal investigator behaviour category

\begin{tabular}{|lcccc|}
\hline & $\begin{array}{c}\text { Year of First Publication } \\
\text { (Range) }\end{array}$ & $\begin{array}{c}\text { Year of First Publication } \\
\text { (Median) }\end{array}$ & $\begin{array}{c}\text { Median } \boldsymbol{h} \text { - } \\
\text { index }\end{array}$ & $\begin{array}{c}\text { Median m- } \\
\text { quotient }\end{array}$ \\
\hline Research Supporters & $1994-2007$ & 2005 & 3 & 0.67 \\
Research Pursuers & $2000-2005$ & 2000 & 6 & 0.57 \\
Research Designers & $1983-1998$ & 1986 & 27 & 1.19 \\
Research Adapters & $1980-2005$ & 1992 & 14 & 0.78 \\
\hline
\end{tabular}

Table 5 - Summary of funding activity for each principal investigator behaviour category

\begin{tabular}{|lcc|}
\hline & Median Number of Projects Funded (2005- & \\
& 2009) & Median Project Award \\
\hline Research Supporters & 2 & $€ 155,000$ \\
Research Pursuers & 1.5 & $€ 160,500$ \\
Research Designers & 3.5 & $€ 381,833$ \\
Research Adapters & 3 & $€ 240,000$ \\
\hline
\end{tabular}




\section{Appendix 1}

\begin{tabular}{|c|c|}
\hline \multicolumn{2}{|c|}{ Funding Body Descriptions of the Principal Investigator } \\
\hline Funding Body & Description \\
\hline $\begin{array}{l}\text { Science Foundation } \\
\text { Ireland (SFI) }\end{array}$ & $\begin{array}{l}\text { "The lead applicant responsible for the scientific and technical direction } \\
\text { of the research programme and the submission of reports to SFI. They } \\
\text { are the primary contact point and have primary fiduciary responsibility } \\
\text { and accountability for carrying out the research within the funding } \\
\text { limits awarded and in accordance with the terms and conditions of SFI." }\end{array}$ \\
\hline $\begin{array}{l}\text { Irish Research } \\
\text { Council }\end{array}$ & $\begin{array}{l}\text { "Principal Investigators shall be full-time members of the academic staff, } \\
\text { either permanent or on temporary contracts of sufficient duration to } \\
\text { cover the period of the project, of a (legitimate) third-level institution. } \\
\text { They must be in a position to devote adequate time to the management } \\
\text { and realisation of the project. The actual scope of involvement by the } \\
\text { Principal Investigators in each project will be considered by the } \\
\text { Assessment Board (AB) in their evaluation of the expertise of the } \\
\text { proposed research team." }\end{array}$ \\
\hline $\begin{array}{l}\text { European Research } \\
\text { Council (ERC) }\end{array}$ & $\begin{array}{l}\text { "The Principal Investigator is the individual that may assemble a team to } \\
\text { carry out the project under his/her scientific guidance." }\end{array}$ \\
\hline $\begin{array}{l}\text { European Medicines } \\
\text { Agency (EMA) }\end{array}$ & $\begin{array}{l}\text { "The Principal Investigator is the person with the responsibility for the } \\
\text { coordination of investigators at different centres participating in a } \\
\text { multicentre trial, or the leading investigator of a monocentre trial, or the } \\
\text { coordinating (principal) investigator signing the clinical study report." }\end{array}$ \\
\hline $\begin{array}{l}\text { National Science } \\
\text { Foundation (NSF) }\end{array}$ & $\begin{array}{l}\text { "The Principal Investigator is the individual designated by the grantee, } \\
\text { and approved by NSF, who will be responsible for the scientific or } \\
\text { technical direction of the project. The term "Principal Investigator" } \\
\text { generally is used in research projects, while the term "Project Director" } \\
\text { generally is used in science and engineering education and other } \\
\text { projects." }\end{array}$ \\
\hline $\begin{array}{l}\text { National Aeronautics } \\
\text { \& Space } \\
\text { Administration } \\
\text { (NASA) }\end{array}$ & $\begin{array}{l}\text { "A Principal Investigator is the individual(s) a research organization } \\
\text { designates as having an appropriate level of authority and responsibility } \\
\text { for the proper conduct of the research, including the appropriate use of } \\
\text { funds and administrative requirements such as the submission of } \\
\text { scientific progress reports to the agency." }\end{array}$ \\
\hline \multicolumn{2}{|c|}{ Ivy League Descriptions of the Principal Investigator } \\
\hline Funding Body & Description \\
\hline $\begin{array}{l}\text { University of } \\
\text { Pennsylvania }\end{array}$ & $\begin{array}{l}\text { "A principal investigator is an individual designated by the University } \\
\text { and approved by the sponsor to direct a project funded by an external } \\
\text { sponsor. S/he is responsible and accountable to the University and } \\
\text { sponsor for the proper programmatic, scientific, or technical conduct of } \\
\text { the project and its financial management." }\end{array}$ \\
\hline Dartmouth & I Investigator has primary responsibility for achieving the \\
\hline
\end{tabular}




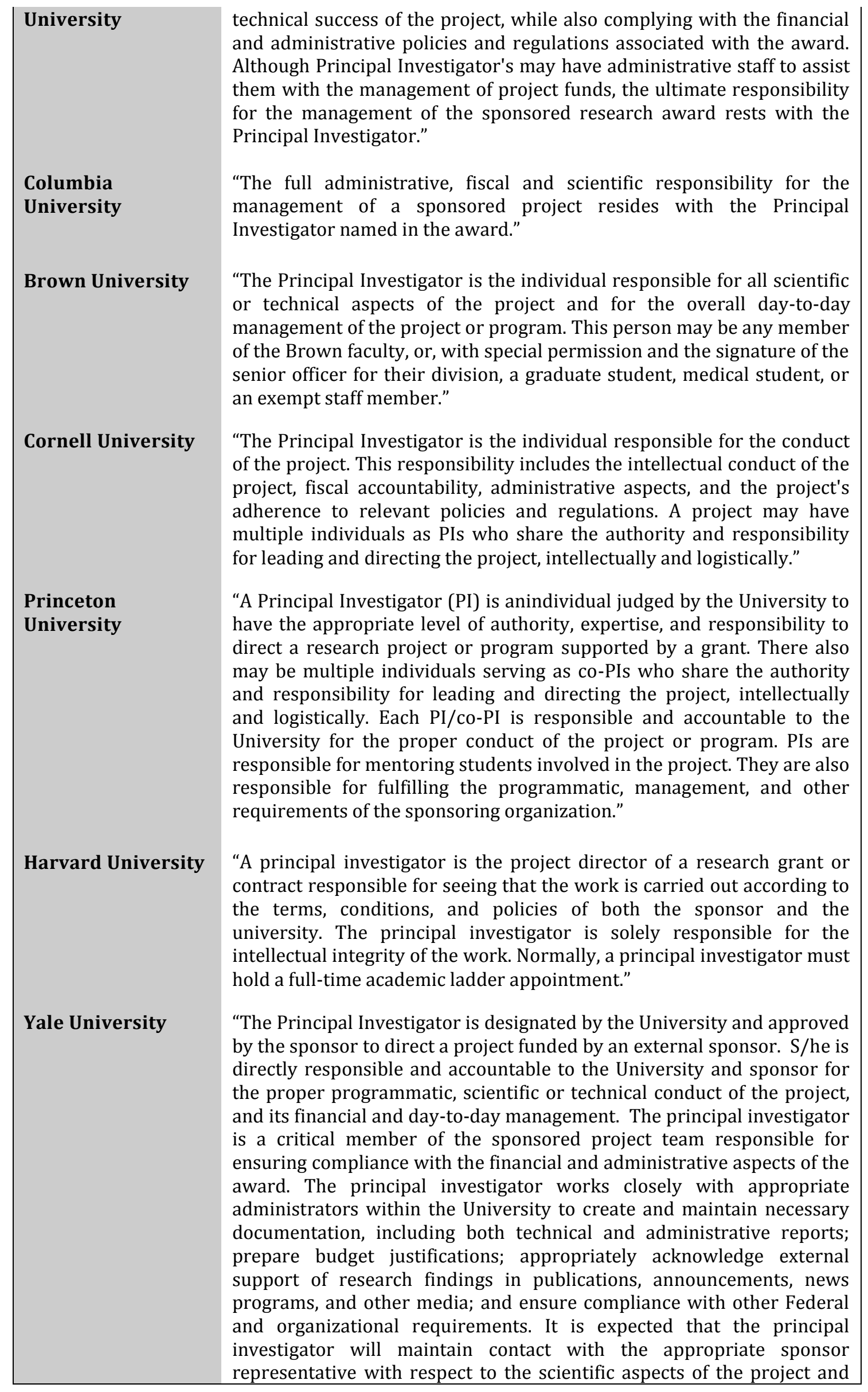


